\title{
Variation in Polyunsaturated Fatty Acids Composition of Persian Walnut
}

\author{
L. Carl Greve, Gale McGranahan, Janine Hasey, Ronald Snyder, Kathy Kelly, \\ David Goldhamer, and John M. Labavitch \\ Department of Pomology, University of California, Davis, CA 95616
}

Additional index words. Juglans regia, plant breeding, geographic effects, irrigation, irradiance

\begin{abstract}
The variation in polyunsaturated fatty acid content of walnut (Juglans regia L.) oils was determined by analysis of samples isolated from specimens growing in four germplasm collections [California (55 cultivars), Washington (64 seedlings), China (12 cultivars), and France ( 20 cultivars)]. In addition, the impact of within-state geographic differences on oil composition was examined by comparing samples from three California cultivars ('Ashley', 'Hartley', and 'Franquette') grown in three locations. Local environmental effects on oil composition of 'Chico' were also examined by comparing 1) samples collected from shaded and sun-exposed locations of the same trees and 2) samples collected from trees subjected to three irrigation regimes. Polyunsaturated fatty acid content, as a percentage of total fatty acids, ranged from $47.2 \%$ in nuts from PI 142323 from France to $81.0 \%$ in 'Ashley' from California. However, our data indicate that environment, genotype, nut maturity, and their interactions all contribute significantly to variation in the degree of unsaturation of walnut oil.
\end{abstract}

The walnut's tendency for rancidification is probably related to the high concentration of unsaturated fatty acids found in walnut oil. The kernel is $\approx 65 \%$ oil, on a dry-weight basis, although this figure varies year to year (Greve and Labavitch, 1985). Of the fatty acids in walnut oil, as much as $90 \%$ is comprised of linoleic plus linolenic acids (C18:2 and C18:3, respectively) (Table 1, from Greve and Labavitch, 1985). These two polyunsaturated fatty acids (PUFA), in conjunction with naturally occurring enzyme systems (e.g., lipase and lipoxygenase), have been shown to be contributors in the rancidification of various plant and animal oils (Davies et al., 1987; Karahadian and Lindsay, 1989; Rennie and Tanner, 1989; Rockland et al., 1961). Various workers have assumed that a reduction in the concentration of these (and other less prominent) PUFA in edible oils would lead to a significant stabilization of these commodities (Dahmer et al., 1989; Hammond and Fehr, 1981; Karahadian and Lindsay, 1989; Rennie and Tanner, 1989).

There has been considerable interest in the genetic manipulation of the oil composition of several oil-producing commodities. Crops where the variation in oil composition has been examined with the aim of genetically improving oil stability

Table 1. Percent distribution of fatty acids in cold-pressed oil from typical California walnut cultivars. ${ }^{2}$

\begin{tabular}{lccccc}
\hline \hline & \multicolumn{5}{c}{ Fatty acid } \\
\cline { 2 - 6 } Cultivar & C16 & C18 & C18:1 & C18:2 & C18:3 \\
\hline Hartley & 3.2 & 0.8 & 11.8 & 67.3 & 17.4 \\
Vina & 2.4 & 0.6 & 7.0 & 72.0 & 17.6 \\
Ashley & 4.4 & 0.6 & 5.7 & 69.0 & 20.6 \\
Chandler & 2.3 & 0.7 & 6.1 & 66.2 & 25.0 \\
Howard & 3.2 & 0.7 & 6.6 & 72.0 & 18.5 \\
Eureka & 3.6 & 0.8 & 7.7 & 71.0 & 16.3 \\
\hline \hline
\end{tabular}

${ }^{2}$ Data from the 1985 harvest.

Received for publication 20 May 1991. Accepted for publication 9 Oct. 1991. We thank K. Woeste and N. Willits for statistical assistance and E. Germain, S.K. Xi, and A.M. Davis for providing the walnuts analyzed in this study. This work was partially funded by the Walnut Marketing Board and the U.S. Dept. of Agriculture/Agricultural Research Service Specific Cooperative Agreement no. 58-91H2-8-131. The cost of publishing this paper was defrayed in part by the payment of page charges. Under postal regulations, this paper therefore must be hereby marked advertisement solely to indicate this fact. include soybean (Glycine max L.), nut palms, sunflower (Helianthus annuus L.), peanut (Arachis hypogaea L.), sesame (Sesamum indicum L.), Cuphea, and Brassica (Auld et al., 1990; Branch et al., 1990; Hammond and Fehr, 1984; Jones, 1984; Soldatov, 1976; Tashiro et al., 1990; Thompson et al., 1990). One of the earliest such efforts involved a mutagenic breeding program aimed at reducing the concentration of $\mathrm{C} 18: 3$ in soybean oil. An initial survey showed that the concentration of this PUFA in most commercial cultivars was $\approx 9.0 \%$. Individuals selected from mutagenesis experiments had concentrations ranging from $9.9 \%$ to 3.870. Selections with decreased PUFA concentrations have been used in breeding to decrease the PUFA content of commercial cultivars (Hammond and Fehr, 1984).

Another approach has been used by the growers of oil palms. Clonally propagated cultivars for the production of palm oil have only recently been available to researchers and growers. Analysis of the oils from these cultivars and wild-type plants has shown that there is large variation in the fatty acid composition of the oil produced. Analysis of specific crosses has shown that oil composition is genetically controlled and breeders are now attempting to isolate individuals from wild types with favorable oil-producing characters. Individuals with oils containing 270 to 1470 PUFA have been reported. Within the palm industry, there have been successful attempts to increase the percentage of unsaturated fatty acids in some of the more fruitful varieties by selective breeding to generate more liquid oil (Jones, 1984).

Sunflower oil, because of its high concentration of C18:2 (640 to $720 \mathrm{~g} \cdot \mathrm{kg}^{-1}$ oil) and absence of cholesterol, is extremely popular on the world market for use in salad dressing and other applications that do not require heating during processing. The high concentration of $\mathrm{C} 18: 2$ renders the oil unstable to heating and, thus, limits its use for other food applications. Soldatov (1976) isolated individuals that had greatly increased concentrations of C18:1 (oleic acid) and a proportionally lower concentration of C18:2. These variants have been used extensively in breeding programs, leading to cultivars with stable oil compositions having as much as $820 \mathrm{~g}$ oleic acid/kg oil. Analysis of the heritability of this trait indicates that control of this aspect

Abbreviations: ET, full water use; PTB, packing-tissue-brown; PUFA, polyunsaturated fatty acids; REGWF, Ryan-Einot-Gabriel-Welsch multiple F test. 
of the sunflower's oil composition is directed by two genes, one partially dominant major gene and one modifier gene that must be present in the homozygous condition for expression of high oleic acid concentrations in relatively cold regions (Miller et al., 1987). These examples show that oil composition from seed crops can be manipulated by breeding strategies. The objective of our study was to determine whether there is genetic variation in percent PUFA in walnuts.

\section{Materials and Methods}

The study was divided into three parts. The first part consisted of an analysis of the percentage of total fatty acids that consist of PUFA in walnuts obtained from germplasm collections located in the states of California and Washington, and in France and China. The second part was based on analysis of nuts from three standard California cultivars growing in three geographic locations in California. The third part was based on the analysis of nuts, from sun or shade from one cultivar in one geographic location, that were obtained from trees exposed to various irrigation regimes. For the latter two parts, nuts were collected weekly over 3 to 4 months that bracketed the normal harvest date. Thus, we were able to examine the potential diversity of PUFA in germplasm worldwide as well as variation affected by environmental conditions.

Germplasm collection evaluation. Nuts from a French germplasm collection located on the Ile d'Arsins $(\approx \mathrm{km}$ from Bordeaux) were provided by Ing. E. Germain, France (Table 2). These nuts were collected from 20 cultivars representing a wide range of genetic diversity. Nuts from China were provided by S.K. Xi, Forestry Institute, Beijing, from a collection near Beijing and represented 12 cultivars found in eastern China (Table 2). Two collections in the United States were sampled. One was from Central Ferry, Wash., provided by Albert M. Davis, U.S. Dept. of Agriculture, Pullman, and consisted of 64 seedlings of USSR origin. The other from the Univ. of California, Davis, which consisted of 55 cultivars of diverse genetic background (Table 2).

Nuts were harvested at maturity (hull-split), dried to a water content of $\approx 8 \%$, and sent to Davis where the kernels were removed and frozen until analysis. Samples for analysis consisted of a single kernel. Three to four samples were analyzed for each genotype.

Locations within California. Nuts of three standard cultivars ('Ashley', 'Hartley', and 'Franquette') were collected from commercial orchards in Sutter and Stanislaus counties and from the germplasm collection at Davis. Collections were made about weekly from mid-August, before the packing tissue had turned brown (a phonological marker), through normal harvest $(90 \%$ hull-split). Kernels were removed and frozen within $2 \mathrm{~h}$ of collection and transported frozen to Davis for analysis. Each sample consisted of one to two sound kernels. Four samples were analyzed per collection date per cultivar for each location.

Environment within one location. Nuts were collected from 6-year-old 'Chico' walnut trees growing on the Kearney Agriculture Field Station near Fresno, Calif. The trees were in the second year of an on-going study to evaluate the effect of deficit irrigation on walnuts and had been exposed to one of three irrigation rates, $100 \%$ of full water use (ET), 66\% ET, and 33\% ET (Goldhamer et al., 1987a, 1987b). Samples were collected from both sun-exposed and completely shaded areas of the canopies at about weekly intervals, beginning in late June and continuing until 4 weeks past harvest for each irrigation regime. A sample consisted of two kernels. Two samples per treatment were analyzed.

Table 2. Genotypes and collection location of walnuts evaluated for polyunsaturated oil content.

\begin{tabular}{|c|c|c|c|}
\hline \multicolumn{4}{|c|}{ Bordeaux, France } \\
\hline Adams 10 & Hartley & Payne & Sibisel 39 \\
\hline Chase D9 & Marbot & PI 142323 & Sibisel 44 \\
\hline Franquette & Mat $12-1$ & PI 265712 & Sopore \\
\hline Geisenheim 139 & Milotai 10 & Plodivski & Sorrente \\
\hline Geisenheim 1239 & Mitsuru & Shinrei & \\
\hline \multicolumn{4}{|c|}{ Beijing, China } \\
\hline Dalian 78103 & Liao $\mathrm{He} 2$ & Shandong W78-17-5 & Shanxi 8447 \\
\hline Dalian 50609 & Shandong N1-3 & Shanxi 8701 & Shanxi seedling \\
\hline Liao $\mathrm{He} 1$ & Shandong N1-7 & Shanxi 8702 & Shanxi seedling \\
\hline \multicolumn{4}{|c|}{$\begin{array}{c}\text { Pullman, Wash. } \\
76 \text { and } 32 \text { seedlings of PI } 364372\end{array}$} \\
\hline \multicolumn{4}{|c|}{ Davis, Calif. } \\
\hline Adams & Hartley & PI 159568 & UC52-1 \\
\hline Amigo & Hodges & Pioneer & UC53-57 \\
\hline Ashley & Howard & Placentia & UC53-59 \\
\hline Blackmer & Howe & Scharsch Franquette & UC54-124 \\
\hline Chandler & Idaho & Serr & UC56-176 \\
\hline Chico & Lompoc & Sinensis no. 5 & UC56-224 \\
\hline Concha & Marchetti & Sinensis no. 7 & UC61-25 \\
\hline Conway Mayette & Meylan & Sunland & UC63-153 \\
\hline Early Ehrhardt & Midland & Tehama & UC63-378 \\
\hline Erhorn & $0-13-1048$ & Trinta & UC63-432 \\
\hline Eureka & $0-20-1072$ & Vina & UC66-178 \\
\hline Franquette & Payne & XXX Mayette & UC67-11 \\
\hline Graves Franquette & Pedro & UC49-46 & UC67-13 \\
\hline Gustine & PI 18256 & & UC68-104 \\
\hline
\end{tabular}


Analysis of oil composition. Kernels were lyophilized and the weight of each sample was determined. Oils were obtained by cold-pressing the kernel tissue in a $2.86-\mathrm{cm}$-diameter test cylinder with pressure applied by a hydraulic press. The applied force was limited to $35,150 \mathrm{kpa}$ for $2 \mathrm{~min}$. The resulting aqueousoil emulsion $(200 \mu \mathrm{l})$ was collected from the test cylinder using a Pasteur pipette and immediately placed in a screw-top (glass) centrifuge tube $(13 \times 100 \mathrm{~mm})$ containing $0.5 \mathrm{ml}$ hexane with $100 \mu \mathrm{g} \mathrm{C17:0}$ and $500 \mu \mathrm{g}$ butylhydroxytoluene (BHT) added as an antioxidant. After the oil emulsion was added to the tube, the mixture was agitated vigorously and centrifuged at $680 \times g$ for 2 rein; then, the organic phase was removed and concentrated by evaporating the hexane with a stream of dry $\mathrm{N}_{2}$ at 30C. The isolated oil sample (containing the BHT and the C17:0 internal standard) was hydrolyzed and methylated as described by Labavitch et al. (1982).

Analysis of the resulting fatty acid methyl esters was done by GLC using a Perkin-Elmer 8320 gas chromatography fitted with a DB-23 capillary column $(30 \mathrm{~m}$ x $0.25 \mathrm{~mm}$ id.; J \& W Scientific, Folsom, Calif.). Hydrogen gas was used as the carrier and detection was made by a flame ionization detector. Quantitation was performed by a Perkin-Elmer Sigma 10 data analyzer.

Data analysis. Data were analyzed using proc GLM, proc varcomp, and the Ryan-Einot-Gabriel-Welsch multiple F test (REGWF) on SAS (SAS Institute, Cary, N.C.).

\section{Results and Discussion}

Germplasm collection evaluation. We report here data from nuts collected in 1987. However, the data are similar to those obtained by us in earlier, less extensive studies in 1984 and 1980 (Greve and Labavitch, 1985). Both genotype and area of collection were highly significant sources of variation in percent polyunsaturated oils in walnuts from international collections. Both contributed equally to the variation. The collection in Davis had the highest percent PUFA and was significantly different from the Washington collection (Table 3). The nuts from China and France were not different from each other but were lower in PUFA than those from Washington and California.

Nuts from four of the 20 cultivars from France had $>70 \%$ PUFA. These were 'Shinrei', Japan (74.8\%); 'Hartley', United States (71.6\%); 'Geisenheim 1239', Germany (71.3\%); and 'Franquette', France (70.7\%). Four cultivars had nuts with $<60 \%$ PUFA: 'Chase D9', Oregon, or 'Plodivski', Bulgaria (tag lost) (57.8\%); 'Mat 12-1', Israel (57.3\%); 'Milotai 10', Hungary (55.6\%); and PI 142323, Poland (47.2\%). The latter was significantly lower (REGWF, $\alpha \leq 0.01)$ than the other cultivars in the collection and had the lowest percent PUFA of all nuts tested. If there is genetic control over percent PUFA, PI 142323 may be a source of low PUFA for breeding.

Nuts of four of the 12 cultivars from China had PUFA levels $>70 \%$. Three of these were from seedlings or selections from Shanxi $(72.1 \%, 71.9 \%, 71.7 \%)$, and one from Liao He $(70.1 \%)$.

Table 3. Percent PUFA in walnuts from international germplasm collections.

\begin{tabular}{lcccr}
\hline \hline Collection & $\mathrm{n}$ & Mean $^{2}$ & Range & $\mathrm{CV}$ \\
\hline California & 55 & $74.9 \mathrm{a}$ & $58.52-81.10$ & 2.33 \\
Washington & 64 & $68.0 \mathrm{~b}$ & $54.45-80.22$ & 1.67 \\
China & 12 & $65.2 \mathrm{C}$ & $51.80-72.13$ & 1.89 \\
France & 20 & $64.8 \mathrm{C}$ & $47.20-74.80$ & 2.44 \\
\hline
\end{tabular}

${ }^{\mathrm{z}}$ Mean separation at $\alpha \leq 0.01$ by REGWF.
One selection from Liao He, at $51.8 \%$, was significantly lower in PUFA (REGWF, $\alpha \leq 0.01$ ) than all the others.

More than 35\% of the 64 seedlings tested from Washington had PUFA levels $>70 \%$ and one (D58-16a no. 1) exceeded $80 \%$. Ten percent were $<60 \%$, the lowest being D58-4A no. 2 at $54.5 \%$ PUFA.

The Davis collection of 55 cultivars and selections had the highest mean percent PUFA, with $89 \%$ of the cultivars at $>70 \%$ PUFA and three cultivars (all selected in California) $>80 \%$ (Ashley, 81.0\%; Amigo, 80.9\%; 67-11, 80.0\%). The lowest percent PUFA was found in 'Conway Mayette' (58.5\%), a Frenchtype cultivar that was significantly different from the next lowest, 'Scharsch Franquette' (65.4\%), also a French cultivar.

Three cultivars in the Davis collection, 'Payne', Hartley', and 'Franquette', were duplicated in the French collection. Although 'Payne' nuts from France had a lower PUFA (64.5\%) than those from California (74.7\%), the 'Hartley' and 'Franquette' were both similar and no significant differences could be detected by analysis of variance.

Geographic locations within California. Cultivar, location of cultivar, and their interaction were all highly significant sources of variation in percent PUFA at the packing-tissue-brown (PTB) and $90 \%$ hull-split stages. At the PTB stage, $68 \%$ of the variation was attributable to the interaction between cultivar and location, whereas at hull-split $>95 \%$ of the variation was due to this interaction. At all locations, the three cultivars differed significantly from each other at the PTB stage, with 'Hartley' highest and 'Ashley' lowest. At hull-split, differences could not be detected between 'Hartley' and 'Franquette'; however, 'Ashley' remained significantly lower. At hull-split (Table 4), cultivars ranked similarly at the Davis (Yolo County) and Sutter County locations, with 'Franquette' highest and 'Ashley' lowest. In Stanislaus County, 'Hartley' was highest and 'Franquette' lowest. When location means were computed over all cultivars, nuts from Stanislaus had the lowest percent PUFA but were not significantly different from those in Sutter.

The percent polyunsaturated fatty acids in the nuts increased for all cultivars as the nuts matured (Fig. 1), and continued increasing after the recommended harvest date (90\% hull-split).

Environment within one geographic location. Maturity and irrigation rate were significant sources of variation in the part of the study that assessed the effect of irradiance (shaded vs. sun-exposed nuts) and irrigation rate $(100 \%, 66 \%$, and 33\% ET) on 'Chico' walnuts as they matured between 24 June and 5 Oct. (Table 5). The interactions between stage of maturity and irradiance, as with irrigation, were also significant. The strongest effect was due to maturity, which accounted for $82 \%$ of the variation. As the nuts matured, the percent PUFA rapidly increased (Fig. 2). Deficit irrigation, i.e., 33\% ET, significantly reduced PUFA content. Although exposure to light was not a

Table 4. Percent PUFA (k SE) in walnuts of three cultivars (at hullsplit) grown at three locations in California.

\begin{tabular}{lcccc}
\hline \hline & \multicolumn{4}{c}{ Location } \\
\cline { 2 - 5 } Cultivar & Davis $^{\mathrm{z}}$ & Sutter & Stanislaus \\
County & County & Mean \\
\hline Hartley & $71.3 \pm \mathrm{t} 1.2$ & $71.0 \pm 0.8$ & $71.2 \pm 0.6$ & $71.1 \mathrm{a}$ \\
Franquette & $72.7 \pm 0.9$ & $75.0 \pm 0.4$ & $64.3 \pm 0.1$ & $70.7 \mathrm{a}$ \\
Ashley & $68.5 \pm 0.3$ & $63.3 \pm 2.2$ & $70.8 \pm 1.5$ & $67.5 \mathrm{~b}$ \\
Meany & $70.8 \mathrm{x}$ & $69.8 \mathrm{xy}$ & $69.8 \mathrm{y}$ & 69.8 \\
\hline
\end{tabular}

${ }^{2}$ Yolo County.

${ }^{y}$ Mean separation at $\alpha \leq 0.01$ REGWF. 

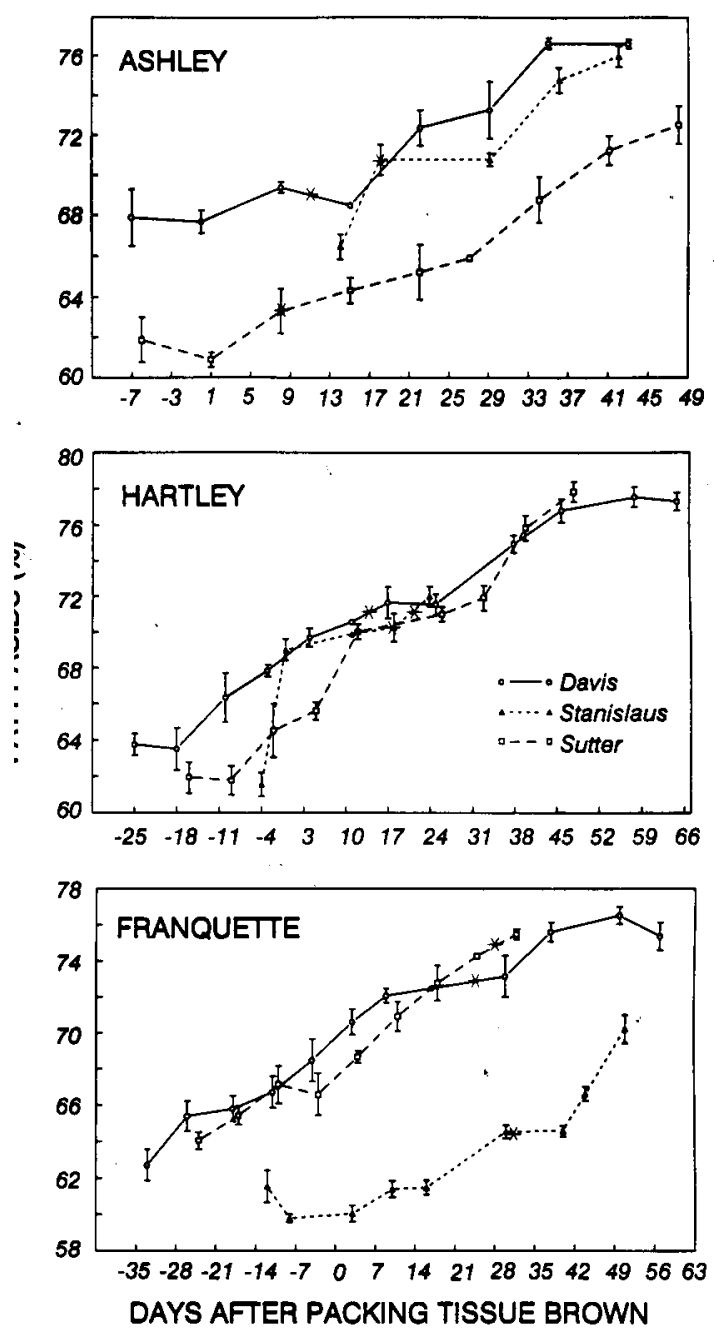

Fig. 1. Percent PUFA in nuts of three cultivars of walnuts as they matured in three locations in California. Each point represents the mean of four samples. (* indicates date of $90 \%$ hull-split, i.e., normal harvest date).

Table 5. Variation in percent PUFA in shaded or sun-exposed 'Chico' walnuts collected at two stages of maturity from trees grown at one of three irrigation rates $(33 \%, 66 \%$, and $100 \%$ ET).

\begin{tabular}{lcrc}
\hline \hline Source & df & MS & F \\
\hline Light & 1 & 0.50 & 0.04 \\
Irrigation & 2 & 81.66 & $6.87^{* *}$ \\
Light $\times$ irrigation & 2 & 26.49 & 2.23 \\
Maturity & 1 & 5947.10 & $500.20^{* *}$ \\
Maturity $\times$ light & 1 & 241.01 & $20.27^{* *}$ \\
Maturity $\times$ irrigation & 2 & 75.09 & $6.32^{* *}$ \\
Maturity $\times$ light $\times$ irrigation & 2 & 17.05 & 1.43 \\
Error & 300 & 11.89 & \\
\hline
\end{tabular}

significant source of variation overall, the interaction between it and maturity was significant because nuts collected from the shaded part of the canopy had a higher percent PUFA as the nuts were maturing, but once the nuts were mature, those exposed to sun had higher percent PUFA (Fig. 3). We recognize that the differences due to exposure to sunlight may reflect differences in temperatures of the nuts at the two locations.

Our data can be taken as evidence that the degree of unsaturation of walnut oil is the consequence of various factors. These include genotype, location, maturation, and stress. Similar in-

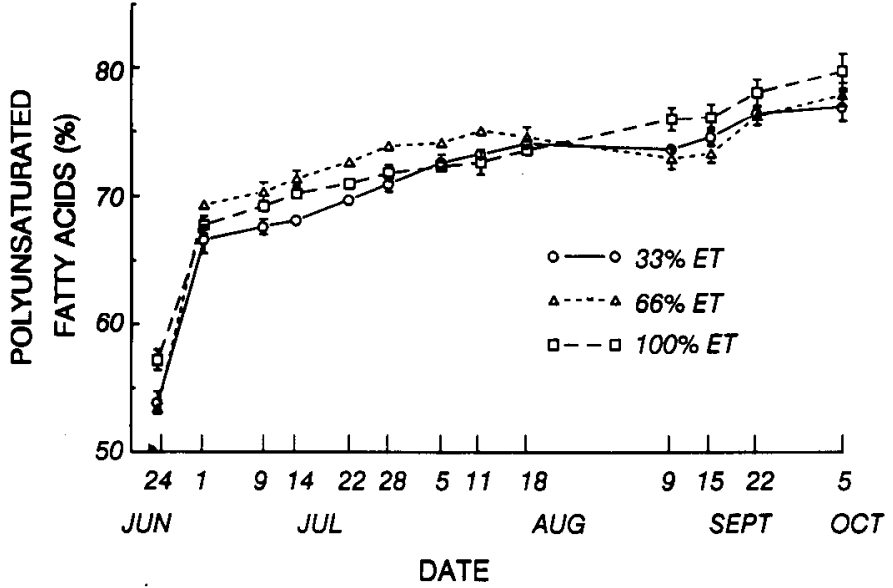

Fig. 2. Percent PUFA in 'Chico' walnuts exposed to various irrigation regimes. Each point represents the mean of eight samples. (HSD $=1.13)$.

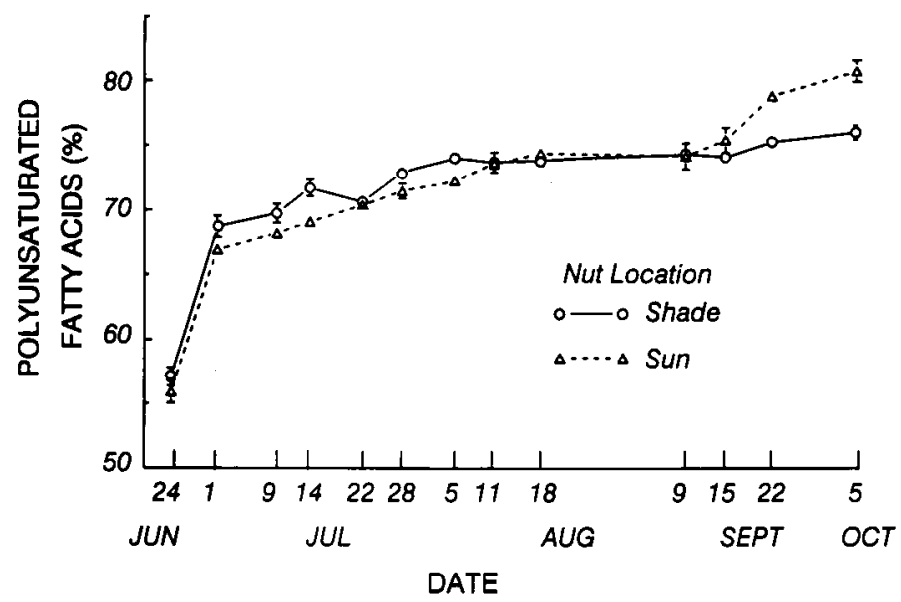

Fig. 3. Percent PUFA in 'Chico' walnuts exposed to sun or shade as they matured. Each point represents the mean of 12 samples. (HSD $=0.77)$.

formation has been reported for the oils of sunflower and soybean (Lajara et al., 1990; Rennie and Tanner, 1989). The study with sunflower examined the influence of latitude and temperature on the degree of unsaturation in oil derived from plants grown in various parts of Spain. In general, sunflowers grown in more northerly regions, or at higher altitude at the same latitudes (cooler regions), produced a seed oil that was significantly more unsaturated than that of seeds grown in more southerly or warmer locales. These observations provide strong evidence that the influence of location (environment) might mask genetic differences if not carefully controlled.

The influence of nut maturation on the degree of unsaturation of walnut oil is clearly shown in Fig. 1. This developmental character, increasing polyunsaturation of the nut oil with increasing maturation, might be exploited if existing cultural practices (e.g., harvest conditions) could be changed toward earlier dates without decreasing the quality or yield of the harvested crop.

\section{Literature Cited}

Auld, D. L., K. Mahler, and D. LeToumeau. 1989. Evaluation of four Brassica germplasm collections for fatty acid composition. J. Amer. Oil Chem. Soc. 66:1475-1479.

Branch, W. D., T. Nakayama, and M. Chinnon. 1990. Fatty acid var- 
iation among U.S. runner type peanut cultivars. J. Amer. Oil Chem. Soc. 67:591-593.

Dahmer, M., P. Fleming, G. Conings, and D. Hildebrand. 1989. A rapid screening method for the determination of the lipid composition of soybean seeds. J. Amer. Oil Chem. Soc. 66:543-548.

Davies, C. S., S.S. Nielson, and N.C. Nielson. 1987. Flavor improvement of soybean preparations by genetic removal of lipoxygenase 2 . J. Amer. Oil Chem. Soc. 61:1428-1433.

Goldhamer, D. A., R. Beede, S. Sibbett, T.M. DeJong, D. Ramos, R.C. Phene, and J. Doyle. 1987a. Second year effects of deficit irrigation on walnut tree performance. Walnut Res. Rpts. Walnut Mktg. Board, Sacramento, Calif. 1987:59-70.

Goldhamer, D.A., R. Beede, S. Sibbett, T.M. DeJong, D. Ramos, R.C. Phene, and J. Doyle. 1987b. Irrigation effects on walnut kernel quality as affected by nut temperatures throughout the season. Walnut Res. Rpts. Walnut Mktg. Board, Sacramento, Calif. 1987:71-80.

Greve, L.C. and J.M. Labavitch. 1985. Development of rancidity in walnuts. Walnut Res. Rpts. Walnut Mktg. Board, Sacramento, Calif. 1985:235-245.

Hammond, E.G. and W.R. Fehr. 1984. Improving the fatty acid composition of soybean oil. J. Amer. Oil Chem. Soc. 61:1713-1716.

Jones, L.H. 1984. Novel palm oils from cloned plants. J. Amer. Oil Chem. Soc. 61:1717-1719.

Karahadian, C. and R.C. Lindsay. 1989. Action of tocopherol type compounds in directing reactions forming flavor compounds in autooxidizing fish oils. J. Amer. Oil Chem. Soc. 66:1302-1308.

Labavitch, J. M., C.M. Heintz, H.L. Rae, and A. Kader. 1982. Physiological and compositional changes associated with maturation in 'Kerman' pistachio nuts. J. Amer. Soc. Hort. Sci. 107:688-692.

Lajara, J. R., U. Diaz, and R.A. Quidiello. 1990. Definite influence of location and climatic conditions on the fatty acid conditions of sunflower oil. J. Amer. Oil Chem. Soc. 67:618-623.

Miller, J. F., D.C. Zimmerman, and B.A. Vick. 1987. Genetic control of high oleic acid content in sunflower oil. Crop Sci. 27:923-926.

Rennie, B.D. and J.W. Tanner. 1989. Fatty acid composition of oil from soybeans grown at extreme temperatures. J. Amer. Oil Chem. Soc. 66:1622-1624.

Rockland, L. B., D.M. Swarthout, and R.A. Johnson. 1961. Studies on English walnuts, Juglans regia III. Food Technol. 15:112-116.

Soldatov, K.I. 1976. Chemical mutagenesis of sunflower breeding. In: Proc. 7th Intl. Sunflower Conf. Krasnodar, USSR. Intl. Sunflower Assn., Vlaardingen, The Netherlands. p. 352-3.57.

Tashiro, T., Y. Fukuda, T. Owasa, and N. Namiki. 1990. Oil and minor components of sesame strains. J. Amer. Oil Chem. Soc. 67:50S 511.

Thompson, A.E., D.A. Dierg, S.J. Knapp, and R. Kleiman. 1990. Variation in fatty acid content and seed weight in some boric acid rich Cuphea species. J. Amer. Oil Chem. Soc. 67:611-617. 